\title{
Development of electrochemical oxidase biosensors based on carbon nanotube-modified carbon film electrodes for glucose and ethanol
}

\author{
Carla Gouveia-Caridade, Rasa Pauliukaite, Christopher M.A. Brett* \\ Departamento de Química, Faculdade de Ciências e Tecnologia, Universidade de Coimbra, 3004-535 Coimbra, Portugal \\ Received 11 December 2007; received in revised form 16 January 2008; accepted 17 January 2008
}

\begin{abstract}
Functionalised multi-walled carbon nanotubes (MWCNTs) were cast on glassy carbon (GC) and carbon film electrodes (CFE), and were characterised electrochemically and applied in a glucose-oxidase-based biosensor. MWCNT-modified carbon film electrodes were then used to develop an alcohol oxidase (AlcOx) biosensor, in which AlcOx-BSA was cross-linked with glutaraldehyde and attached by drop-coating. The experimental conditions, applied potential and $\mathrm{pH}$, for ethanol monitoring were optimised, and ethanol was determined amperometrically at -0.3 $\mathrm{V}$ vs. SCE at pH 7.5. Electrocatalytic effects of MWCNT were observed with respect to unmodified carbon film electrodes. The sensitivity obtained was 20 times higher at carbon film/MWCNT-based biosensors than without MWCNT.
\end{abstract}

(C) 2008 Elsevier Ltd. All rights reserved.

Keywords: Multi-walled carbon nanotubes; Carbon film electrodes; Glucose oxidase; Alcohol oxidase; Electrochemical biosensor

\section{Introduction}

The development of carbon nanotubes (CNTs) for electroanalytical applications is currently a very active multidisciplinary field. During the last 15 years CNTs have attracted enormous interest due to their unique structure, mechanical strength and electronic properties [1-4]. CNTs consist of seamless cylindrical graphite sheets, which can be formed as a single tube of graphite (single-walled carbon nanotubes (SWCNT)), and multi-walled carbon nanotubes (MWCNTs), which consist of several concentric tubes of graphite inside one other. The reactivity of carbon nanotubes has been shown, as would be predicted, to be due only to the edge plane sites and to structural defects on the cylindrical surface of the nanotubes [5].

The chemical stability of CNTs and affinity to biomolecules make them very promising for application in electrochemical sensors and biosensors [6]. As an electrode material, carbon nanotubes have the ability to promote electron transfer reactions with electroactive species in solution [7], showing better electrochemical behaviour than conventional carbon electrodes [8]. It has been shown that CNTs are able to improve the direct

\footnotetext{
* Corresponding author. Tel.: +351 239835295; fax: +351 239835295 .

E-mail address: brett@ci.uc.pt (C.M.A. Brett).
}

electron transfer reaction of some important biomolecules, such as cytochrome $c$ [9-11], myoglobin [12-14], glucose [15-19], catalase [20,21], NADH [22-26], and haemoglobin [27,28], among others.

The insolubility of CNTs in all solvents can be a major drawback to their use in electrochemical sensors and biosensors. Several strategies have been proposed to dissolve CNTs including oxidative treatment [29], polymer wrapping [30], and sidewall functionalisation [31]. Functionalisation of CNTs improves the solubility and processability, giving the opportunity to develop new types of nanotube-based materials [32].

Wrapping CNTs in polymeric chains, besides improving the solubility, also maintains the physical properties of the CNTs. The perfluorosulfonated polymer Nafion ${ }^{\circledR}$ has been extensively used for the modification of electrode surfaces and for the construction of sensors and biosensors. Wang et al. [16] demonstrated the usefulness of Nafion ${ }^{\circledR}$ to solubilise CNTs and they reported an electrocatalytic effect toward hydrogen peroxide, which is of much interest for the operation of oxidase-based amperometric biosensors. Tsai et al. [33] cast MWCNT dispersed in Nafion ${ }^{\circledR}$ on a glassy carbon (GC) electrode to construct an electrochemical sensor for the analytical determination of heavy metals in the presence of surfactants such as SDS and Triton X-100. 
Various electrochemical biosensors have been prepared using CNTs [6]. Most of these have been for glucose, with and without redox mediators. With respect to alcohol biosensors, the only reports, to our knowledge, all use alcohol dehydrogenase, mixing with $\mathrm{NAD}^{+}$cofactor in a MWCNT composite [34], incorporation in a CNT paste electrode [35] or self-assembly on the surface of a glassy carbon electrode modified with SWCNT held in place by polycations and then covered by Nafion ${ }^{\circledR}$ [36].

Another form of carbon also used as support electrode material is that of carbon films coated on a ceramic substrate by pyrolysis-these small and inexpensive electrodes have been electrochemically characterised $[37,38]$ and successfully applied to the development of electrochemical sensors and biosensors, e.g. Refs. [39,40].

The aim of this study is to extend the use of carbon film electrodes (CFE) as substrate electrode material by modifying them with MWCNT to develop an alcohol oxidase (AlcOx)-based biosensor. A casting method for MWCNT was first investigated, based on methods developed for glassy carbon electrodes [41]. The MWCNTs were first functionalised in $\mathrm{HNO}_{3}$ and then dissolved in Nafion ${ }^{\circledR}$. The MWCNT/Nafion ${ }^{\circledR}$ dispersion was then used to develop and optimise a glucose biosensor, using glucose oxidase (GOx) enzyme, on a modified glassy carbon electrode prior to application in developing an alcohol oxidase-based ethanol biosensor on carbon film electrodes.

\section{Experimental}

\subsection{Materials and reagents}

Multi-walled carbon nanotubes were obtained from NanoLab (Newton, MA, USA). Nafion ${ }^{\circledR} 5 \%$ solution in ethanol was from Aldrich (Germany). Glucose oxidase from Asperigilus niger EC1.1.3.4, alcohol oxidase from Hansenula sp. EC1.1.3.13, and bovine serum albumin (BSA) were purchased from Sigma (Germany). 70\% glutaraldehyde (GA) solution in water was from Fluka (Switzerland).

Phosphate buffer or phosphate buffer saline (PBS) solutions, concentration $0.1 \mathrm{M}, \mathrm{pH}$ from 6.0 to 8.5 were prepared from sodium dihydrogenphosphate and disodium hydrogenphosphate and $0.05 \mathrm{M} \mathrm{NaCl}$ (all these reagents from Riedel-de-Haën, Germany). Millipore Milli-Q nanopure water (resistivity $>18 \mathrm{M} \Omega \mathrm{cm}$ ) was used for preparation of all solutions. Experiments were performed at room temperature, $25 \pm 1{ }^{\circ} \mathrm{C}$.

\subsection{Pretreatment of carbon nanotubes}

MWCNTs were purified and functionalised by stirring in $2 \mathrm{M}$ nitric acid solution for $20 \mathrm{~h}$. The solid product was collected on a filter paper and washed several times with nanopure water until the filtrate $\mathrm{pH}$ became nearly neutral. The functionalised MWCNTs obtained were then dried in an oven at $\sim 80^{\circ} \mathrm{C}$ for $24 \mathrm{~h}$. This procedure was performed to ensure complete removal of transition metal ion catalyst, used in the production of nanotubes, as well as of amorphous carbon. Nitric acid also causes significant destruction of carbon nanotubes and introduces $-\mathrm{COOH}$ groups at the ends of, or at the sidewall defects in the nanotube structure [32,41]. After this, 2-mg MWCNT-COOH were dispersed in $1-\mathrm{mL} 1 \% \mathrm{Nafion}^{\circledR}$ in ethanol.

\subsection{Electrode preparation and enzyme immobilisation}

Carbon film cylindrical electrodes were made from carbon film resistors (resistance $\sim 2 \Omega$ ), their preparation protocol is shown in Fig. 1A and is described in detail elsewhere [38,42]. The exposed disc electrode geometric area was $\sim 0.020 \mathrm{~cm}^{2}$. Before use electrodes were electrochemically pretreated by cycling the applied potential between -1.5 and $+1.5 \mathrm{~V}$ vs. SCE in PBS solution for not less than 10 cycles, until stable cyclic voltammograms were obtained.

A glassy carbon electrode with $7 \mathrm{~mm}$ diameter was used to optimise the casting modification procedure. Before use the glassy carbon surface was polished with 1.00 and $0.05 \mu \mathrm{m}$ alumina powder on a polishing cloth.

A volume of $40 \mu \mathrm{L}$ of MWCNT in Nafion ${ }^{\circledR}$ was used to modify the glassy carbon electrode, or MWCNT were attached directly on the surface of the carbon film electrodes without any solvent (Fig. 1B), by gently rubbing the electrode on a filter paper with carbon nanotubes placed on its surface [43]. The surface coverage of MWCNT in the case of attachment with Nafion ${ }^{\circledR}$ at carbon film electrodes was calculated from the peak current for hexaamineruthenium(III) reduction in cyclic voltammograms and was found to be $27 \pm 1 \mathrm{nmol} \mathrm{cm}{ }^{-2}$.

For attaching the enzyme layer, a volume of $4 \mu \mathrm{L}$ enzymeBSA-GA mixture ( $5 \mu \mathrm{L} 10 \%$ GOx solution in $0.1 \mathrm{M} \mathrm{PBS}, \mathrm{pH}$ $7.0+5 \mu \mathrm{L} 10 \%$ BSA solution in $0.1 \mathrm{M} \mathrm{PBS}, \mathrm{pH} 7.0+1 \mu \mathrm{L}$ glycerol $+1 \mu \mathrm{L} 2.3 \% \mathrm{GA}$ in water or $2 \mu \mathrm{L} 5 \%$ AlcOx in $0.1 \mathrm{M} \mathrm{PBS}$, $\mathrm{pH} 7.0+1 \mu \mathrm{L} 10 \%$ BSA solution in $0.1 \mathrm{M}$ PBS, $\mathrm{pH} 7.0+0.5 \mu \mathrm{L}$ glycerol $+0.5 \mu \mathrm{L} 2.3 \% \mathrm{GA}$ in water) was used to modify the GC/CNT or C film/CNT working electrodes (Fig. 1C). The electrodes were left for an hour to dry at room temperature and then immersed in buffer solution for half an hour before the first measurement to dissolve the rest of the unreacted GA. All biosensors were stored in phosphate buffer at $4{ }^{\circ} \mathrm{C}$ while not in use.

\subsubsection{Optimisation of casting method}

Optimisation of the casting mixture was performed on a GC electrode and using GOx. Carbon nanotubes were attached to the GC electrode in different ways, and the amperometric response to glucose was considered as representing the biosensor efficiency. The three procedures tested were:

- GC/MWCNT/GOx: GC was modified by drop-coating with MWCNT dispersed in Nafion ${ }^{\circledR}$ and, after evaporation of the solvent, the GOx-BSA-GA mixture was placed on top of the MWCNT/Nafion ${ }^{\circledR}$ film.

- GC/MWCNT-GOx: GC was modified by drop-coating a mixture of MWCNT-GOx-BSA-GA.

- GC/GOx/MWCNT: The enzyme layer was first placed on top of the GC electrode and, after drying at room temperature, the MWCNTs were then attached to the enzyme layer.

A GC/GOx assembly, in which the enzyme layer was placed directly on top of the GC electrode without MWCNT, was also 


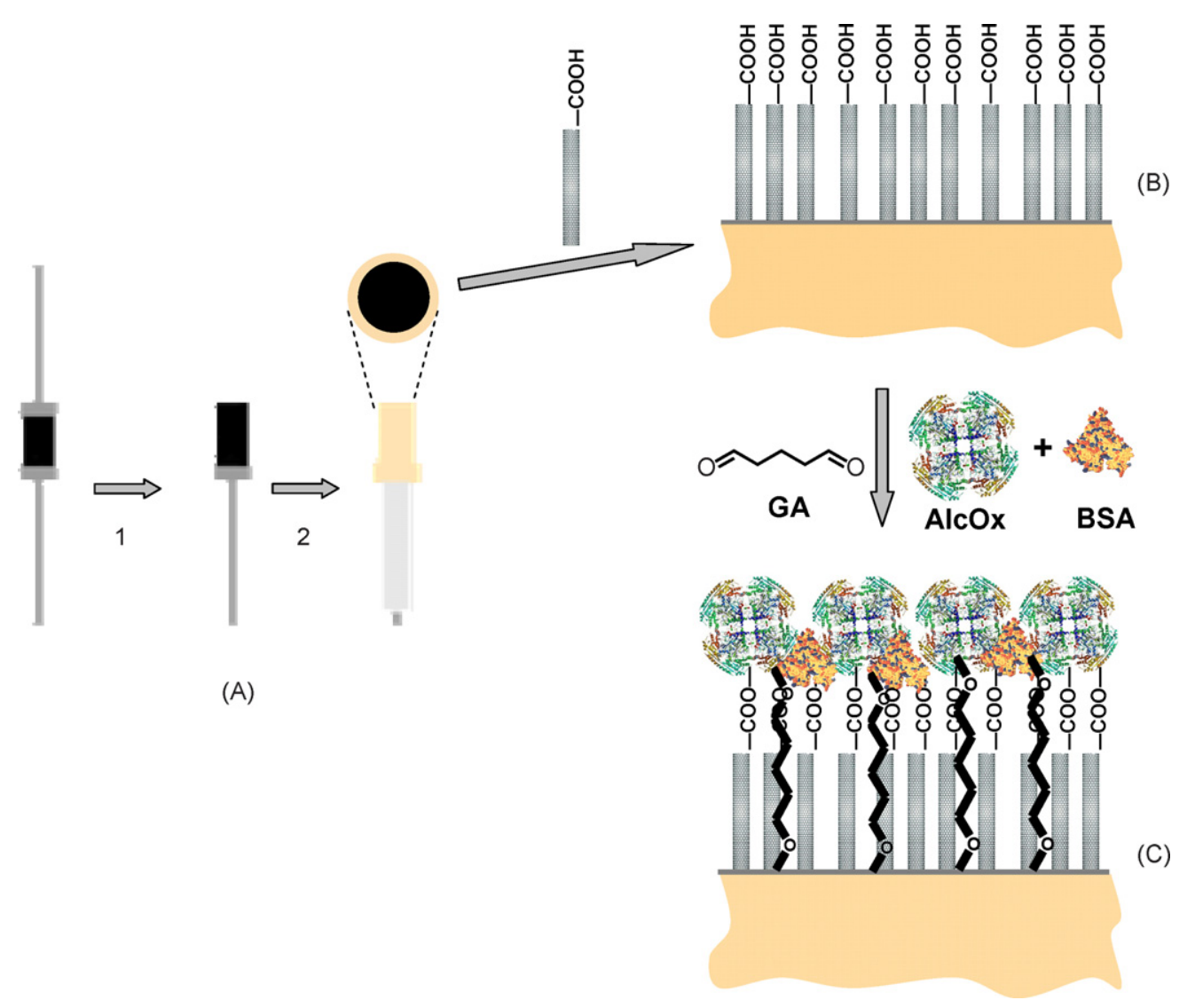

Fig. 1. Scheme of fabrication of the ethanol biosensor. (A) Preparation of the carbon film electrode: removal of one tight-fitting metal cap (1), and protection of the connecting wire and other metal cap by a plastic sheath and epoxy resin (2). (B) Modification of carbon film disc electrode with -COOH functionalised carbon nanotubes without solvent. (C) Cross-linking of alcohol oxidase (AlcOx) and BSA mixture with glutaraldehyde (GA) on top of the carbon nanotubes.

prepared, to enable comparison with the MWCNT-modified electrodes. Amperometric measurements were performed at $+0.70 \mathrm{~V}$ vs. SCE, where electrooxidation of $\mathrm{H}_{2} \mathrm{O}_{2}$ formed in the enzyme-catalysed reaction occurs.

\subsection{Instruments and methods}

A three-electrode electrochemical cell of $15 \mathrm{~mL}$ volume was used for electrochemical measurements. It contained the carbon film or the glassy carbon working electrode, a platinum foil as counter electrode and a saturated calomel electrode (SCE) as reference. Measurements were performed using a computer-controlled $\mu$-Autolab Type II potentiostat/galvanostat with GPES 4.9 software (Eco Chemie, Netherlands).

\section{Results and discussion}

\subsection{MWCNT casting method for glucose biosensor}

A good casting method for MWCNT on carbon film electrodes was first investigated, based on methods developed for glassy carbon electrodes [41]. However due to the small volume required for electrode modification $(1 \mu \mathrm{L})$ difficulties arose in placing the solutions containing the dispersion of MWCNT on the top of the electrode, and it was necessary to develop strategies for immobilising the carbon nanotubes and the enzyme layer on the carbon film electrode surface.

\subsubsection{Glassy carbon electrode support}

The optimisation of the casting mixture was performed on a GC electrode with the well-known and stable GOx enzyme. Carbon nanotubes were attached to the GC electrode in different ways as described in Section 2. The amperometric response to electrooxidation of $\mathrm{H}_{2} \mathrm{O}_{2}$ at $+0.70 \mathrm{~V}$ vs. SCE produced in the enzyme-catalysed oxidation of glucose was used to evaluate the biosensor efficiency.

The results of measurements carried out are presented in Table 1, and they show that the best biosensor activity was obtained when the GOx-BSA mixture was deposited on top of the MWCNT. The sensitivity to glucose at this biosensor was 17 times higher than without any MWCNT. When MWCNTs were attached on the top of the enzyme layer, the sensitivity of the biosensor was the same as without CNT, showing that the CNT completely covered the enzyme layer and, consequently, contact of analyte with the enzyme was poor.

When MWCNT were mixed with the GOx-BSA-GA mixture and deposited together on the GC electrode, the response to glucose was much lower than in the case of GOx drop-coated in a separate layer on top of the CNT. This decrease in response was 
Table 1

Calibration data at different CNT-GOx biosensors

\begin{tabular}{|c|c|c|c|c|c|}
\hline Biosensor assembly composition & Linear range $(\mathrm{mM})$ & Sensitivity $\left(\mu \mathrm{A} \mathrm{cm}^{-2} \mathrm{mM}^{-1}\right)$ & $R^{2}$ & Detection limit $(\mu \mathrm{M})$ & $K_{\mathrm{M}}(\mathrm{mM})$ \\
\hline GC/GOx & $0.05-1.10$ & 0.52 & 0.998 & 8.1 & 2.2 \\
\hline GC/CNT/GOx & $0.05-1.10$ & 9.43 & 0.997 & 9.3 & 1.9 \\
\hline GC/CNT-GOx & $0.05-1.00$ & 2.39 & 0.997 & 14.0 & 2.5 \\
\hline GC/GOx/CNT & $0.05-1.00$ & 0.49 & 0.998 & 16.2 & 2.2 \\
\hline
\end{tabular}

Applied potential $+0.70 \mathrm{~V}$ vs. SCE; supporting electrolyte $0.1 \mathrm{M}$ PBS, pH 7.0.

probably caused by partial blocking of the enzyme and poorer contact between the enzyme and the carbon nanotubes.

\subsubsection{Carbon film electrode support}

The next step was employing CFE as substrate material. The diameter of the CFE disc was $1.5-\mathrm{mm}$ which made it difficult to place the CNT-Nafion ${ }^{\circledR}$ mixture accurately on the disc and control the amount CNT at the electrode surface experiments (such as those described below) showed that the amount of MWCNT deposited was variable. Therefore it was decided to attach the functionalised MWCNT directly to carbon film electrode surface without any solvent, as in Ref. [43], following the procedure in Section 2 and finally a volume of $1 \mu \mathrm{L}$ of a $1 \%$ Nafion ${ }^{\circledR}$ solution (as binder) or the enzyme-BSA-GA mixture was drop-coated on top.

Cyclic voltammograms of the CFE/MWCNT/Nafion ${ }^{\circledR}$ assembly were recorded in $3 \mathrm{mM}$ hexaamineruthenium(III) in order to evaluate the electrochemical behaviour of the modified electrode (see Fig. 2). A fully reversible redox behaviour of hexaamineruthenium(III) was observed, with the cathodic and anodic peaks situated at $\sim-0.220$ and $-0.160 \mathrm{mV}$, respectively, suggesting ideal reversibility at the electrode, as was also observed with $\mathrm{Fe}(\mathrm{CN}) 6^{3-14-}$ at MWCNT-modified electrodes [44]. A linear dependence of peak current on square root of scan rate was found with a slope of $142 \mu \mathrm{A} \mathrm{V}^{-1 / 2} \mathrm{~s}^{1 / 2}$. The electroactive area of the CFE/MWCNT/Nafion ${ }^{\circledR}$ assem-

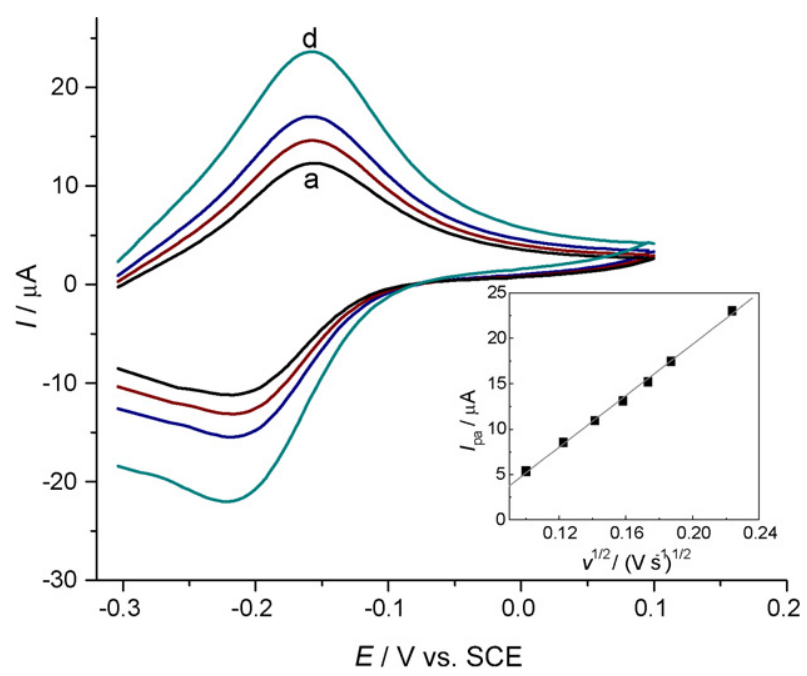

Fig. 2. Cyclic voltammograms of $3 \mathrm{mM} \mathrm{Ru}\left(\mathrm{NH}_{3}\right)_{6}{ }^{3+}$ in $0.1 \mathrm{M} \mathrm{KCl}$ at $\mathrm{CFE} / \mathrm{CNT} / \mathrm{Nafion}{ }^{\circledR}$ at different scan rates from 0.025 to $0.05 \mathrm{~V} \mathrm{~s}^{-1}$ (a-d) after baseline subtraction. Inset: dependence of anodic peak current on the square root of scan rate. bly, calculated from the reduction peak current obtained in $3 \mathrm{mM}$ hexaamineruthenium(III) solution was $\sim 0.060 \mathrm{~cm}^{2}$, using a diffusion coefficient of $9.1 \times 10^{-6} \mathrm{~cm}^{2} \mathrm{~s}^{-1}$ [45], which was 3 times higher than the electroactive/geometric area of the carbon film electrode, $\sim 0.020 \mathrm{~cm}^{2}$, and was 30 times higher than the electroactive area of CFE/Nafion ${ }^{\circledR}\left(1 \%\right.$ Nafion $\left.^{\circledR}\right), \sim 0.002 \mathrm{~cm}^{2}$. Comparison of these data shows that Nafion ${ }^{\circledR}$ film blocks some electroactive centres of the carbon film electrode.

A glucose biosensor was then prepared by binding the solid functionalised MWCNT to the carbon film with the enzyme-BSA-GA mixture, in the same sequence as was found to be the best at GC electrode supports.

It is known that CNT promote direct electron transfer in the case of GOx [17], so amperometric testing of the CFE/MWCNT-GOx-BSA-GA electrode was performed at $0 \mathrm{~V}$ vs. SCE. It was found that $\mathrm{H}_{2} \mathrm{O}_{2}$ is reduced at this potential at CFE/MWCNT-Nafion ${ }^{\circledR}$ (Fig. 3), but there is a positive change in current, corresponding to oxidation, at the biosensor after addition of aliquots of glucose solution. Moreover, decreasing the applied potential to $-0.45 \mathrm{~V}$, the oxidation current increased and the linear range of amperometric response decreased, as seen in Fig. 3. This confirms that direct electron transfer is taking place at CNT as in Ref. [17], so that no redox mediator is required. At $-0.45 \mathrm{~V}$, regeneration of $\mathrm{GOx}-\mathrm{FAD}$ takes place at carbon substrates $[19,46]$.

As seen from Fig. 3, hydrogen peroxide reduction occurs at $0.0 \mathrm{~V}$, showing the catalytic effect of CNT. However, the

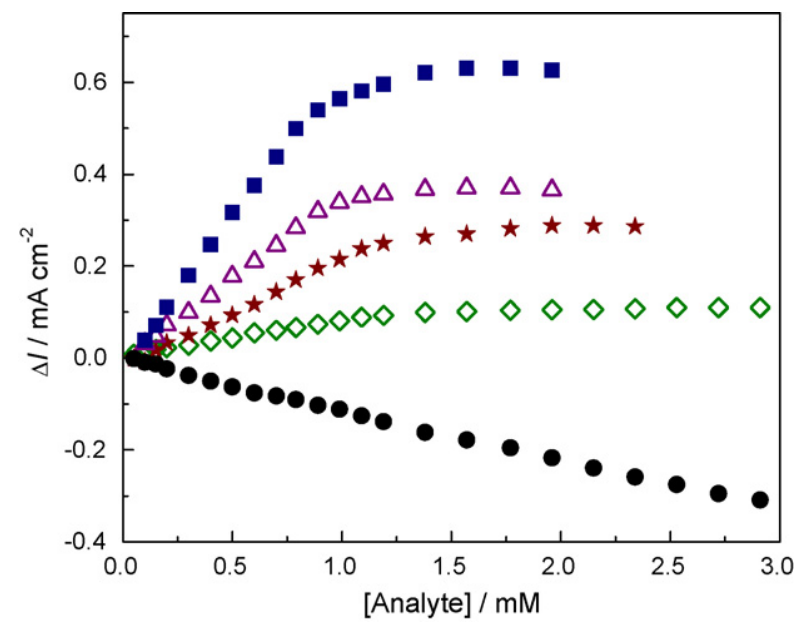

Fig. 3. Amperometric response to $\mathrm{H}_{2} \mathrm{O}_{2}$ at CFE/CNT-Nafion ${ }^{\circledR}$ at $0.0 \mathrm{~V}$ vs. $\mathrm{SCE}(\bullet)$ and to glucose at CFE/CNT-GOx-BSA-GA at $0.0 \mathrm{~V}(\diamond),-0.1 \mathrm{~V}(\star)$, $-0.2 \mathrm{~V}(\triangle)$, and $-0.45 \mathrm{~V}(\boldsymbol{\square})$ vs. SCE supporting electrolyte $0.1 \mathrm{M}$ PBS, pH 7.0. 
Table 2

Calibration data at various CFE-CNT-GOx biosensors; at different applied potentials, supporting electrolyte $0.1 \mathrm{M}$ PBS, pH 7.0

\begin{tabular}{|c|c|c|c|c|c|c|}
\hline Potential (V) & Analyte & Linear range $(\mathrm{mM})$ & Sensitivity $\left(\mu \mathrm{Acm}^{-2} \mathrm{mM}^{-1}\right)$ & $R^{2}$ & Detection limit $(\mu \mathrm{M})$ & $K_{\mathrm{M}}(\mathrm{mM})$ \\
\hline $0.0(\mathrm{CNT})$ & $\mathrm{H}_{2} \mathrm{O}_{2}$ & - & 106 & 0.998 & 15.5 & - \\
\hline $0.0(\mathrm{CNT} / \mathrm{GOx})$ & Glucose & $0.05-1.2$ & 75.0 & 0.998 & 7.1 & 1.7 \\
\hline$-0.10(\mathrm{CNT} / \mathrm{GOx})$ & Glucose & $0.1-1.1$ & 237 & 0.998 & 5.1 & 2.0 \\
\hline$-0.20(\mathrm{CNT} / \mathrm{GOx})$ & Glucose & $0.1-0.9$ & 364 & 0.998 & 2.8 & 1.5 \\
\hline-0.45 (CNT/GOx) & Glucose & $0.1-0.8$ & 666 & 0.999 & 2.2 & 1.7 \\
\hline
\end{tabular}

response at the biosensor with MWCNT was significantly lower than that to added $\mathrm{H}_{2} \mathrm{O}_{2}$ but, nevertheless, the sensitivity to glucose at the biosensor was higher at -0.1 or $-0.2 \mathrm{~V}$ than at $+0.7 \mathrm{~V}$, where hydrogen peroxide oxidation takes place at conventional carbon electrodes, see Tables 1 and 2, and the substrate-enzyme reaction had typical Michaelis-Menten kinetics. A potential value in the middle of the range of the best response, $-0.15 \mathrm{~V}$ vs. SCE, was chosen for further investigations. The response to glucose at separate biosensors prepared in the same way varied up to $10 \%$, which was attributed to different surface areas owing to variations in the mass fraction of MWCNT attached to the electrode supports.

The linear range at $-0.15 \mathrm{~V}$ vs. SCE at the CFE/MWCNTGOx-BSA-GA biosensor was from 0.05 to $0.9 \mathrm{mM}$, the sensitivity was $289 \mu \mathrm{Acm}^{-2} \mathrm{mM}^{-1}$, the limit of detection was $5.0 \mu \mathrm{M}$ and the apparent Michaelis-Menten constant was $2.4 \mathrm{mM}$. These calibration parameters were more suitable for glucose monitoring than at $+0.7 \mathrm{~V}$ vs. SCE in terms of sensitivity and detection limit.

\subsection{Ethanol biosensor}

\subsubsection{Optimisation of operational conditions}

Alcohol oxidase was used for the development of an electrochemical ethanol biosensor. The enzyme-catalysed reaction produces acetaldehyde and hydrogen peroxide:

$\mathrm{C}_{2} \mathrm{H}_{5} \mathrm{OH}+\mathrm{O}_{2} \stackrel{\mathrm{AlcOx}}{\longrightarrow} \mathrm{CH}_{3} \mathrm{CHO}+\mathrm{H}_{2} \mathrm{O}_{2}$

First, the CFE was used by itself, without MWCNT, to procure the best experimental conditions for using AlcOx. Enzyme was immobilised in the same way as GOx, cross-linked with GA from a solution of AlcOx and BSA in a 1:1 ratio. The influence of applied potential was studied for the most common experimental conditions used for oxidases, in $0.1 \mathrm{M}$ PBS solution, $\mathrm{pH}$ 7.0 (Fig. 4(a)). A good operating potential without any mediator was found to be $-0.45 \mathrm{~V}$ vs. SCE where regeneration of FAD takes place, as in the case of GOx (see above), and the response was much higher than that for electro-oxidation of $\mathrm{H}_{2} \mathrm{O}_{2}$ at $+0.75 \mathrm{~V}$, formed during the enzymatic reaction (Fig. 4(a), inset). Therefore an applied potential of $-0.45 \mathrm{~V}$ was used for $\mathrm{pH}$ optimisation.

Phosphate buffer solutions of analytical concentration $0.1 \mathrm{M}$ with $\mathrm{pH}$ values from 6.0 to 8.5 were used for determination of the best $\mathrm{pH}$ value, the $\mathrm{pH}$ giving the best response being between 7.5 and 8.0 (Fig. 4(b)). Thus, pH 7.5 was chosen for the further development of the ethanol biosensor with MWCNT. Similar optimum $\mathrm{pH}$ values have been reported for optical alcohol biosensors based on alcohol oxidase [47,48]. However, the $\mathrm{pH}$ values vary depending on the assay and increase with increase in aliphatic chain length of the alcohol [48].

The response of the CFE/MWCNT/AlcOx biosensor was tested at $\mathrm{pH}$ 7.5. The dependence of the amperometric signal on the applied potential was examined in the range -0.5 to $+0.8 \mathrm{~V}$ vs. SCE, Fig. 5. Higher currents were obtained at the MWCNT-modified electrode, compared to the unmodified one, for all the potentials in Fig. 5. This can be also observed in
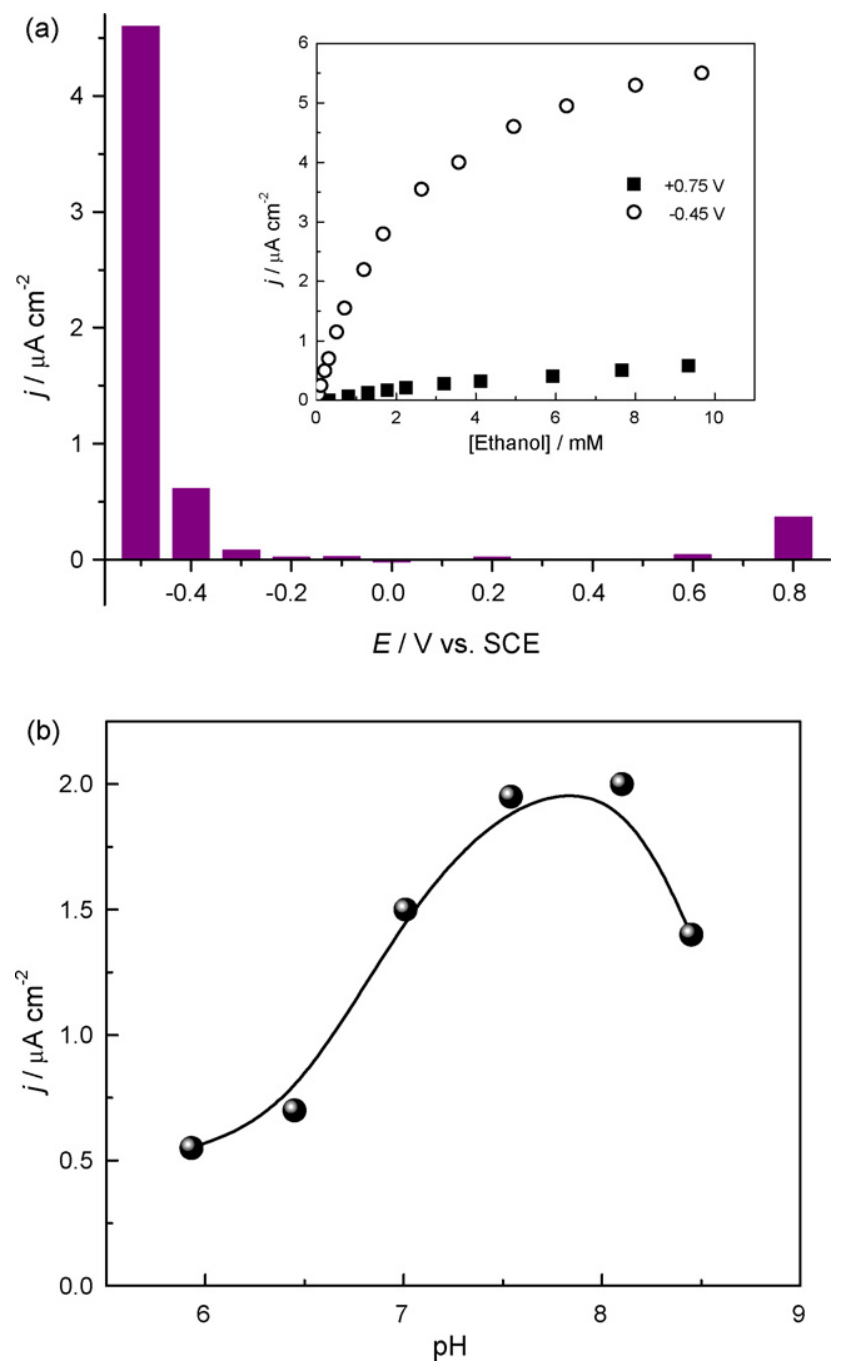

Fig. 4. Optimisation of CFE/AlcOx-BSA-GA electrode (a) operating potential in $0.1 \mathrm{M}$ PBS, $\mathrm{pH} 7.0+1 \mathrm{mM}$ ethanol and (b) $\mathrm{pH}$ in $0.1 \mathrm{M} \mathrm{PBS}+0.3 \mathrm{mM}$ ethanol at $-0.45 \mathrm{~V}$ vs. SCE. Inset of (a) shows calibration curves of ethanol in $0.1 \mathrm{M}$ PBS, pH 7.0 at $(\bigcirc)-0.45 \mathrm{~V}$ and $(\mathbf{\square})+0.75 \mathrm{~V}$ vs. SCE. 


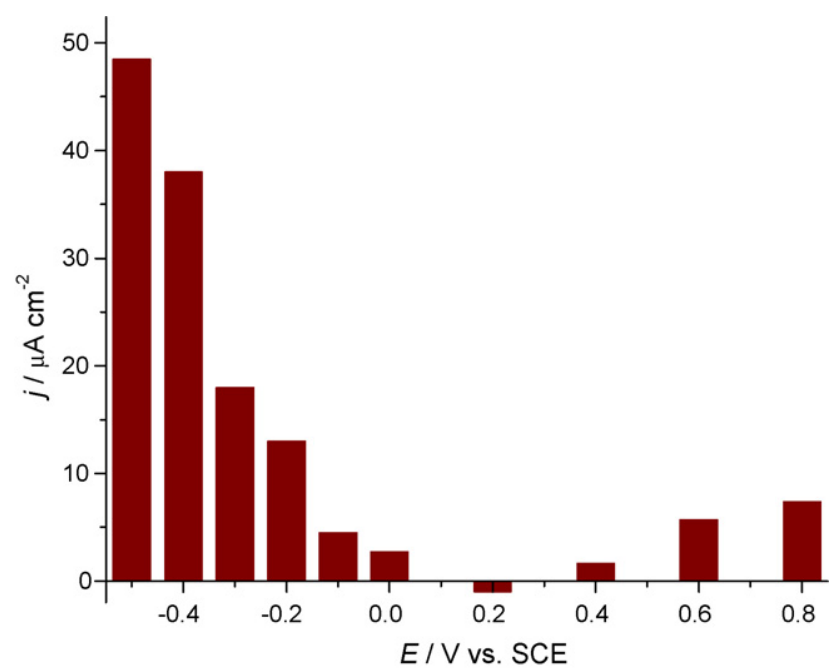

Fig. 5. Optimisation of operating potential at CFE/MWCNT/AlcOx-BSA-GA electrode in $0.1 \mathrm{M}$ PBS, pH 7.5 +1.0 mM ethanol.

the cyclic voltammograms in Fig. 6 recorded at the modified and unmodified MWCNT biosensor with $6 \mathrm{mM}$ ethanol in solution. The reduction current at the MWCNT biosensor increases after ethanol addition in the negative potential region, although no clearly defined cyclic voltammetric peak appears as it does in the case of the biosensor without carbon nanotubes. However, the MWCNT biosensor gives a well-defined response to ethanol at $-0.20 \mathrm{~V}$, while at the CFE biosensor the response to the presence of ethanol starts only at a more negative potential of $-0.39 \mathrm{~V}$. Although the highest current response in amperometric measurements to ethanol addition was at $-0.45 \mathrm{~V}$, partly due to the reaction of FAD itself, it was decided to choose an operating potential of $-0.30 \mathrm{~V}$ since a good current response to ethanol is still obtained and the background current is much lower.

\subsubsection{Amperometric response to ethanol}

The CFE/MWCNT/AlcOx biosensor was applied to the amperometric determination of ethanol at $-0.30 \mathrm{~V}$ vs. SCE. After stabilisation of the baseline current, ethanol was injected into the buffer solution. The calibration curve obtained for ethanol is shown in Fig. 7, the linear part being described by the equation:

$\Delta j\left(\mu \mathrm{Acm}^{-2}\right)=1.88( \pm 0.77)+44.5( \pm 0.99)[$ ethanol $]$

with a correlation coefficient of 0.998 . The linear range was up to $1.4 \mathrm{mM}$, and the detection limit was $86 \mu \mathrm{M}$. The apparent Michaelis-Menten constant $\left(K_{\mathrm{M}}\right)$, determined from the Lineweaver-Burk plot, was $2.2 \mathrm{mM}$. The data obtained with the same enzyme at carbon film electrodes without MWCNT and with poly(neutral red) redox mediator under identical conditions lead to a linear range and apparent Michaelis-Menten constant with lower values than at the biosensor with MWCNT-the linear range is up to $0.6 \mathrm{mM}$ and $K_{\mathrm{M}}$ is $2.1 \mathrm{mM}$ [49]. The kinetics of alcohol oxidase also depends on the immobilisation method, as reported in Ref. [48]: $K_{\mathrm{M}}$ for AlcOx increased from $1.5 \mathrm{mM}$ (free AlcOx in solution) to $6.8 \mathrm{mM}$ after its electrochemical immobili- (a)
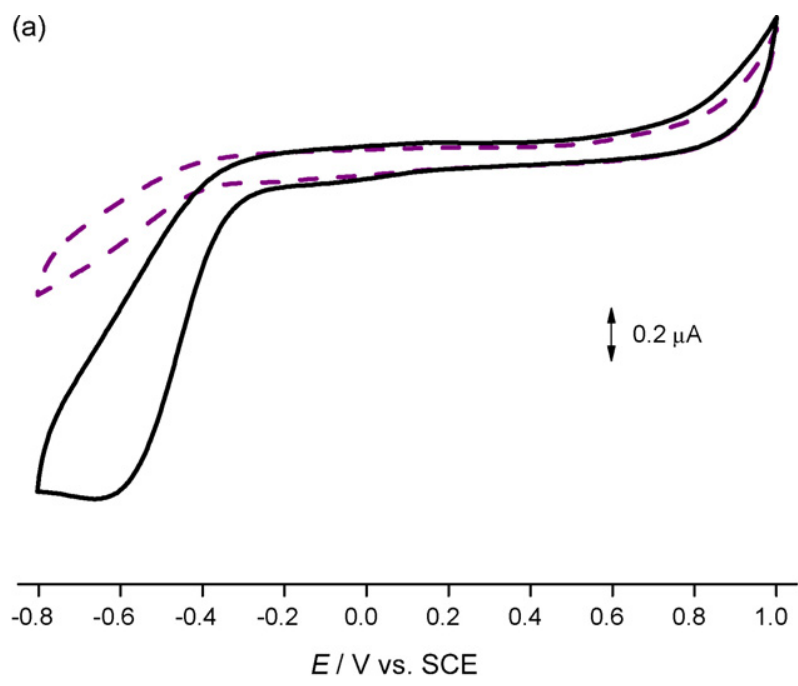

(b)

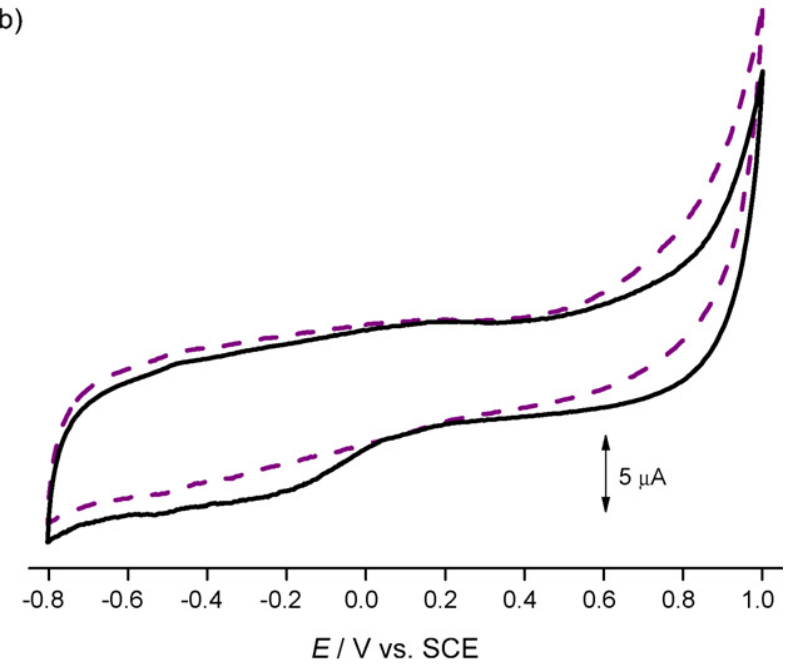

Fig. 6. Cyclic voltammograms at carbon film biosensor: (a) unmodified and (b) modified with MWCNT in 0.1 M PBS solution, pH 7.5 (solid line), and after addition of $6.0 \mathrm{mM}$ of ethanol (dashed line).

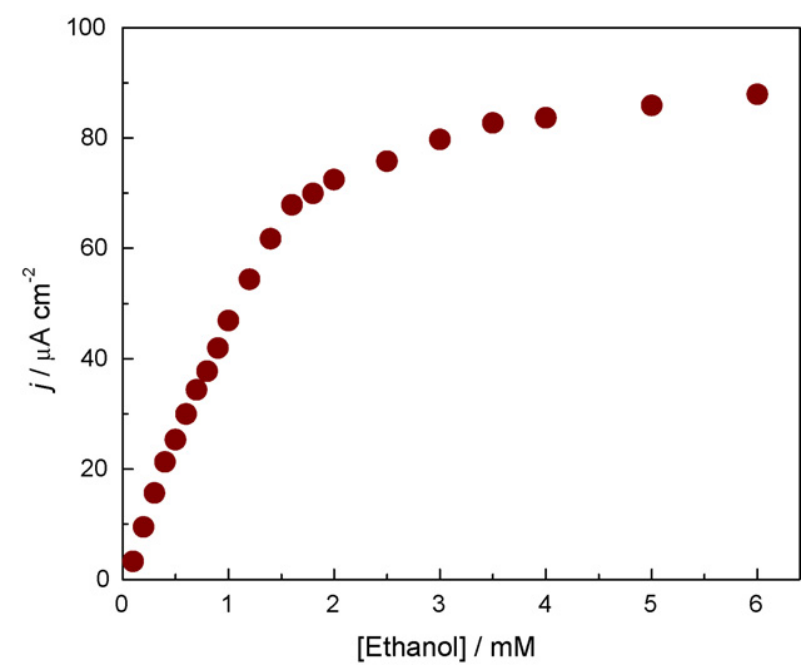

Fig. 7. Calibration curve obtained with CFE/CNT/AlcOx biosensor in $0.1 \mathrm{M}$ PBS pH 7.5, at $-0.30 \mathrm{~V}$ vs. SCE. 
sation into polypyrrole. However, the critical dependence of the kinetics is on the enzyme nature, i.e. which organism AlcOx is taken from. For example, the apparent Michaelis-Menten constant of AlcOx from different mutants of yeast Hansenula polymorpha varied from 1.3 to $12.1 \mathrm{mM}$ for ethanol [50].

The calibration parameters for the $\mathrm{CFE} / \mathrm{AlcO}$ x biosensor without MWCNT obtained at $-0.45 \mathrm{~V}$ (best potential for the unmodified biosensor), in Fig. 2, were a linear range up to $\sim 1.0 \mathrm{mM}$, sensitivity of $2.23 \pm 0.05 \mu \mathrm{A} \mathrm{cm}^{-2} \mathrm{mM}^{-1}$ and detection limit of $37 \mu \mathrm{M}$. Thus, the sensitivity obtained with the MWCNT biosensor was 20 times higher than without MWCNT, even at an applied potential closer to zero, and was more than 50 times higher than the biosensor with poly(neutral red) mediator [49].

Reproducibility studies at three biosensors, prepared in the same way, showed variations of up to $30 \%$, which can be a limitation to the use of carbon nanotube biosensors prepared by attaching solid CNT to electrode surfaces. However, individual calibration of each sensor can easily be done together with use of the standard addition method for unknown samples, which surmounts this possible drawback.

\subsubsection{Operational lifetime and biosensor selectivity}

The stability of the enzyme biosensor was tested daily during 3 weeks. The biosensors were stored in buffer at $4{ }^{\circ} \mathrm{C}$ while not in use. After this time there was a decrease of $70 \%$ of the initial sensitivity value. At biosensors without MWCNT but with poly(neutral red) mediator [49], a similar reduction is seen. However, the lack of stability of alcohol oxidase is well known [51] and both this study and the results in Ref. [49] represent an improvement with respect to previous results regarding stability.

Selectivity is another important parameter to analyse when developing an electrochemical biosensor. The relative amperometric response of the CFE/MWCNT/AlcOx biosensor to ethanol in the presence of some common interferents in food and beverages is shown in Table 3 . All the compounds tested were present at concentrations of $0.8 \mathrm{mM}$ with an ethanol concentration of $0.4 \mathrm{mM}$ and showed a small interference, except in the case of ascorbic acid where an increase of $\sim 30 \%$ in the response was obtained. Considering wine as a sample matrix, this is not a problem since ascorbate is present in wine in a much lower concentration than ethanol.

Table 3

Interference effect of various compounds on the assay of ethanol at CFE/ MWCNT/AlcOx

\begin{tabular}{ll}
\hline Interferent & $\begin{array}{l}\text { Relative response to the analyte in the } \\
\text { presence of the interferents }(\%)\end{array}$ \\
\hline Acetic acid & 100 \\
Ascorbic acid & 131 \\
Citric acid & 100 \\
Lactic acid & 105 \\
Malic acid & 100 \\
Oxalic acid & 111 \\
Tartaric acid & 107 \\
\hline
\end{tabular}

Ratio 1:2 of ethanol to interferent.

\section{Conclusions}

The best casting method of functionalised multi-walled carbon nanotubes has been investigated on glassy carbon and on carbon film electrodes. The most effective method for glassy carbon was mixing MWCNTs with Nafion ${ }^{\circledR}$, whereas at carbon films, immobilisation of solid MWCNTs was best. Optimisation of the operation of the biosensing system with carbon nanotubes was first carried out with GOx and the optimal conditions were found to be a potential of $-0.15 \mathrm{~V}$ vs. SCE and $\mathrm{pH} 7.0$.

The MWCNT were then used to develop an AlcOx-based ethanol biosensor. The optimal conditions for sensor operation were similar to those for glucose except that a more negative potential of $-0.30 \mathrm{~V}$ vs. SCE was used. Electrocatalytic effects of MWCNT were observed in relation to the unmodified carbon film electrode. Although there was a higher detection limit for ethanol of $86 \mu \mathrm{M}$ at the CFE/MWCNT/AlcOx compared with $37 \mu \mathrm{M}$ at CFE/AlcOx, there was a significant increase in sensitivity by a factor of twenty, which augurs well for future application of these sensors.

\section{Acknowledgements}

Financial support from Fundação para a Ciência e Tecnologia (FCT), project PTDC/QUI/65255/2006, POCI 2010 (co-financed by the European Community Fund FEDER) and ICEMS (Research Unit 103), is gratefully acknowledged. CGC and RP thank FCT for a PhD grant (SFRH/BD/18659/2004) and a postdoctoral fellowship (SFRH/BPD/27075/2006), respectively.

\section{References}

[1] C.N.R. Rao, B.C. Satishkumar, A. Govindaraj, M. Nath, Chemphyschem 2 (2001) 78

[2] R.H. Baughman, A.A. Zakhidov, W.A. de Heer, Science 297 (2002) 787.

[3] E. Katz, I. Willner, Chemphyschem 5 (2004) 1085.

[4] J.J. Gooding, Electrochim. Acta 50 (2005) 3049.

[5] G.G. Wildgoose, C.E. Banks, H.C. Leventis, R.G. Compton, Microchim. Acta 152 (2006) 187.

[6] G.A. Rivas, M.D. Rubianes, M.C. Rodríguez, N.F. Ferreyra, G.L. Luque, M.L. Pedano, S.A. Miscoria, C. Parrado, Talanta 74 (2007) 291.

[7] P.J. Britto, K.S.V. Santhanam, P.M. Ajayan, Bioelectrochem. Bioenerg. 41 (1996) 121.

[8] Q. Zhao, Z.H. Gan, Q.K. Zhuang, Electroanalysis 14 (2002) 1609.

[9] J.X. Wang, M.X. Li, Z.J. Shi, N.Q. Li, Z.N. Gu, Anal. Chem. 74 (2002) 1993.

[10] G.C. Zhao, Z.Z. Yin, L. Zhang, X.W. Wei, Electrochem. Commun. 7 (2005) 256.

[11] Y.J. Yin, P. Wu, Y.F. Lu, P. Du, Y.M. Shi, C.X. Cai, J. Solid State Electrochem. 11 (2007) 390.

[12] G.C. Zhao, L. Zhang, X.W. Wei, Z.S. Yang, Electrochem. Commun. 5 (2003) 825 .

[13] L. Zhang, G.C. Zhao, X.W. Wei, Z.S. Yang, Chem. Lett. 33 (2004) 86.

[14] Y.F. Lu, Y.J. Yin, P. Wu, C.X. Cai, Acta Phys. Chim. Sin. 23 (2007) 5.

[15] A. Guiseppi-Elie, C.H. Lei, R.H. Baughman, Nanotechnology 13 (2002) 559.

[16] J. Wang, M. Musameh, Y.H. Lin, J. Am. Chem. Soc. 125 (2003) 2408.

[17] C.X. Cai, J. Chen, Anal. Biochem. 332 (2004) 75.

[18] F. Patolsky, Y. Weizmann, I. Willner, Angew. Chem. Int. Ed. 43 (2004) 2113 . 
[19] X.L. Luo, A.J. Killard, M.R. Smyth, Electroanalysis 18 (2006) 1131.

[20] L. Wang, J.X. Wang, F.M. Zhou, Electroanalysis 16 (2004) 627.

[21] A. Salimi, A. Noorbakhsh, M. Ghadermarz, Anal. Biochem. 344 (2005) 16.

[22] M. Musameh, J. Wang, A. Merkoci, Y.H. Lin, Electrochem. Commun. 4 (2002) 743.

[23] J. Chen, J.C. Bao, C.X. Cai, T.H. Lu, Chin. Chem. Lett. 14 (2003) 1171.

[24] J. Chen, C.X. Cai, Chin. J. Chem. 22 (2004) 167.

[25] J. Wang, Electroanalysis 17 (2005) 7.

[26] K.S. Prasad, J.C. Chen, C. Ay, J.M. Zen, Sens. Actuator B: Chem. 123 (2007) 715.

[27] J. Chen, C.X. Cai, Chin. Chem. Lett. 15 (2004) 813.

[28] G.C. Zhao, M.Q. Xu, J. Ma, X.W. Wei, Electrochem. Commun. 9 (2007) 920.

[29] W. Zhao, C.H. Song, P.E. Pehrsson, J. Am. Chem. Soc. 124 (2002) 12418.

[30] M.J. O'Connell, P. Boul, L.M. Ericson, C. Huffman, Y.H. Wang, E. Haroz, C. Kuper, J. Tour, K.D. Ausman, R.E. Smalley, Chem. Phys. Lett. 342 (2001) 265.

[31] R.K. Saini, I.W. Chiang, H.Q. Peng, R.E. Smalley, W.E. Billups, R.H. Hauge, J.L. Margrave, J. Am. Chem. Soc. 125 (2003) 3617.

[32] P. Papakonstantinou, R. Kern, L. Robinson, H. Murphy, J. Irvine, E. McAdams, J. McLaughlin, T. McNally, Fullerene Nanotube Carbon Nanostruct. 13 (2005) 91.
[33] Y.C. Tsai, J.M. Chen, F. Marken, Microchim. Acta 150 (2005) 269.

[34] J. Wang, M. Musameh, Anal. Lett. 36 (2003) 2041.

[35] M.D. Rubianes, G.A. Rivas, Electroanalysis 17 (2005) 73.

[36] S. Liu, C.H. Cai, J. Electroanal. Chem. 602 (2007) 103.

[37] O.M.S. Filipe, C.M.A. Brett, Electroanalysis 16 (2004) 994.

[38] C. Gouveia-Caridade, C.M.A. Brett, Electroanalysis 17 (2005) 549.

[39] M.E. Ghica, C.M.A. Brett, Anal. Lett. 39 (2006) 1527.

[40] C. Gouveia-Caridade, C.M.A. Brett, J. Electroanal. Chem. 592 (2006) 113.

[41] N.S. Lawrence, R.P. Deo, J. Wang, Electroanalysis 17 (2005) 65.

[42] C.M.A. Brett, L. Angnes, H.D. Liess, Electroanalysis 13 (2001) 765.

[43] A. Salimi, A. Noorbakhsh, S. Soltanian, Electroanalysis 18 (2006) 703.

[44] J.M. Nugent, K.S.V. Santhanam, A. Rubio, P.M. Ajayan, Nano Lett. 1 (2001) 87.

[45] F. Marken, J.C. Eklund, R.G. Compton, J. Electroanal. Chem. 395 (1995) 335.

[46] G.D. Withey, A.D. Lazareck, M.B. Tzolov, A. Yin, P. Aich, J.I. Yeh, J.M. Xu, Biosens. Bioelectron. 21 (2006) 1560.

[47] R.C.W. Lau, M.H.F. Choi, J.Z. Lu, Talanta 48 (1999) 321.

[48] H.B. Yildiz, L. Toppare, Biosens. Bioelectron. 21 (2006) 2306.

[49] M. Barsan, C.M.A. Brett, Talanta 74 (2008) 1505.

[50] K.V. Dmytruk, O.L. Smutok, O.B. Ryabova, G.Z. Gayda, V.A. Sibirny, W Schuhmann, M.V. Gonchar, A.A. Sibirny, BMC Biotechnol. 7 (2007) 33.

[51] N.G. Patel, S. Meier, K. Camman, G.C. Chemnitius, Sens. Actuator B: Chem. 75 (2001) 101. 